\title{
The Concise British Flora in Colour, by W. Keble Martin. Ebury Press \& Michael Joseph, 35s.
}

This is a magnificent tour de force, the great bulk of the British flora illustrated in colour as the life's work of one man, a busy Devonshire vicar, who is due to celebrate his 88th birthday this year. The ferns and their allies are omitted, but the conifers are included. The grasses are, not unreasonably, illustrated only in black and white. The skill with which a dozen or more plants are fitted into one tightly packed plate after another is of a high order. All plants are shown life size and painted from nature. The likenesses are both artistic and reasonably accurate, bearing in mind the variability of many plants, so that a good rendering of one individual may not always represent the whole species; the occasional false colour values may be due either to this factor or (more likely) to the printing.

The text consists of highly concentrated notes, e.g. for the common daisy: "Plants forming a close mat; achenes without pappus. Abundant in short grass. Flo. all the year". Coupled with the excellent likenesses opposite, this should enable the great majority of common flowers to be identified; more critical plants will still need the aid of a more detailed flora. The size of the book $(26 \mathrm{~cm}$. by $19 \mathrm{~cm}$.) will, however, make a haversack necessary for using it in the field.

RICHARD FITTER.

\section{An Introduction to the Natural History of Singapore, by D. S. Johnson. Rayirath Publications, Kuala Lumpur, \$5.00.}

Although in the 1950's Alfred Russel Wallace reported that tigers on Singapore Island killed, on average, a man every day, there are now no large wild mammals there, apart from a few feral pigs. Nevertheless, considering the extent to which the island is populated and industrialised, wild life is well represented, mainly in the considerable extent of forest which constitutes the catchment area round the large lakes or reservoirs and a small area of primary forest on Bukit Timah hill.

Here the mouse deer Tragulus kanchil survives, several species of squirrels and tree shrews, the pangolin Manis javanica, the remarkable flving lemur Cynocephalus variegatus and a variety of other mammals, birds and reptiles too numerous to mention. The insect and other invertebrate life of this area is also very rich, and the catchment area and Bukit Timah jungle have been maintained as nature reserves for a number of years.

A comprehensive book on Singapore's natural history, including plant as well as animal life, is therefore a considerable undertaking, and Dr. Johnson has compressed a great deal of information into a small but well arranged book. Botany occupies only the first 15 of 106 pages, the rest being devoted to animal life, both terrestrial and marine. There is a good list of items for further reading and the book is well indexed, but the figures which illustrate it do not measure up to the quality of the text; they should be replaced by drawings of better quality in future editions.

M. W. F. TWEEDIE.

$\mathbf{F}^{\mathrm{o}}$ children The Big Cats by Desmond Morris (Bodley Head. 13s 6d), is a factual account (including vital statistics) of the Big Five-lion. tiger, leopard, jaguar and snowy leopard, with the cheetah thrown in as being neither big nor small-and illustrated with vigorous and attractive drawings by Barry Driscoll. A chapter on the language of cats tells how a cat's mood can be seen by the position of its ears. 